\title{
Modified Push-out Tests for Determining Shear Strength and Stiffness of HSS Stud Connector-Experimental Study
}

\author{
Amar Prakash ${ }^{*}$, N. Anandavalli, C. K. Madheswaran, N. Lakshmanan \\ CSIR-Structural Engineering Research Centre, Taramani (P.O.), Chennai, 600113, India
}

\begin{abstract}
This paper presents, modified push-out tests conducted for the determination of shear strength and stiffness of high strength steel (HSS) studs. The HSS studs having ultimate strength of $900 \mathrm{MPa}$ and yield strength of $680 \mathrm{MPa}$ are used in the modified push-out specimens. The reinforced concrete slabs of push-out specimens which have provided dimensions as recommended by BS5440 part-v, but with enhanced transverse reinforcement for higher splitting strength. Enhancement of splitting strength is considered due to confinement of the concrete with hoop type transverse reinforcement at smaller spacing. Mander's model is considered to estimate the enhancement in the splitting strength due to increase in the confined compressive strength of concrete. Novelty of this study may be considered in highlighting the importance of confined concrete strength while designing pushout specimens. Experimental value of shear strength of HSS studs is found to fall in between the extreme bounds specified by the Eurocode 4 formulae. Further improvements are possible by the addition of steel fibres concrete in the vicinity of HSS studs embedded in RC slab of push-out specimens.
\end{abstract}

Keywords Push-Out Test, High Strength Steel, Stud Connector, Confinement of Concrete, Splitting Strength

\section{Introduction}

Creative innovation in construction industry together with the advancement of material properties and technologies enabled pursuit of the human challenge to the height (buildings) and span (roofs and bridges) of the structural systems[1]. Steel-concrete composite (SCC) construction, being one among the faster, economical and eco-friendly methods has been extensively used in high rise buildings as well as in medium span bridge decks. In this type of construction, transfer of longitudinal shear between steel beam and reinforced concrete slab is achieved by means of the various types of mechanical devices called as shear connectors. First time composite bridges and composite buildings were reported in the U.S. in the year, 1894. The increasing level of knowledge later enabled development of code provisions, which first appeared for buildings in 1930's as reported by[2] and subsequently for bridges as in[3-6, 24].

Among various types of shear connectors, stud type connectors have been most commonly used in composite construction.

Stud connectors are subjected to flexural and axial forces in resisting the interface forces by means of dowel action. Force transfers in composite structures depend on the strength and stiffness of various components of the composite beam as well as shear connectors. Therefore, it is

* Corresponding author:

amar@serc.res.in (Amar Prakash)

Published online at http://journal.sapub.org/cmaterials

Copyright (C) 2012 Scientific \& Academic Publishing. All Rights Reserved necessary to determine the design parameters namely, shear strength and stiffness for stud connector prior to their use in construction. This task is mostly accomplished by conducting experiments on push-out specimens. Several types of push-out specimens have been studied in past decades and reported in the literature.

Behaviour of stud shear connectors in light weight and normal weight concrete is studied by[7]. Investigation on the strength of push-out specimens have been carried out by[8]. Later,[9] have recommended various empirical equations to include the effect of variation in material strength, on the strength of shear connectors. Effect of transverse reinforcement on the shear strength of stud shear connectors have been investigated by[10] using push-out tests. It has been reported by them that the shear strength is affected by stiffness of transverse reinforcement and not by its strength. Static push-out tests conducted by[11], to determine the ultimate slip and strength of large diameter stud shear connectors. It has been reported that,[5] gives conservative values for the strength of large stud connectors.

It is reported by[12] that the transverse reinforcement provides confinement to the concrete in the vicinity of studs rather than contribution to the strength. Shear stiffness, ultimate slip capacity and shear strength of stud connectors have been determined. The behaviour of stud connectors in high strength and normal strength concrete have been studied by[13]. Studs in normal strength concrete reported to exhibited ductile behaviour as the descending branch was gradual and longer as compared with studs in high strength concrete. Research work of[14] has investigated on the static and fatigue testing on shear connector using push out tests. Re- 
cently,[15] have reported a comprehensive compilation of experimental studies on push-out specimens. It is reported that the equations given in[6] need modifications to comply with experimental trends.

Besides the experimental study on push-out tests, numerical investigations have also been reported in[16] and few others. Push-out test have been simulated using finite element based commercial softwares. Extensive parametric study has also been carried out for various sizes of stud connectors and compressive strength of concrete. It has been concluded from numerical studies that the finite element analysis can be used as a supplement in the determination of the design parameters for stud connectors.

\subsection{Status of Push-out Tests on HSS Stud}

In spite of tremendous experimental research work reported by various researchers, it was observed that the use of high strength steel stud (having ultimate strength as $900 \mathrm{MPa}$ or more) needs further investigations. Authors could not find much about study on HSS studs in the reported literature. As a matter of interest, HSS stud connectors can play significant role where, strength of shear connection governs the design rather than ductility. In the present work four push-out specimens are tested to determine the design shear strength and stiffness of HSS stud connectors. Authors have designed an exclusive push-out test program considering confined strength of concrete. Present push-out test differs in reinforcement, method of casting of concrete and test setup than that reported in existing codes as mentioned earlier. Experimental value of shear strength of HSS studs is found comparable to that with[5].

\subsection{Objectives of the Study}

Objectives of the present study are, (i) to study load-slip behaviour and (ii) to determine the design shear strength and stiffness, of HSS studs using the new approach. The paper highlighted the consideration of confined concrete strength towards enhancement of compressive strength as compared to unconfined strength of concrete. The paper is organized into five sections. Second section explains experimental program. Determination of strength and stiffness for HSS studs is explained in third section in detail. Discussions and observations based on experimental results are given in fourth section. Finally the conclusions are provided in fifth section.

\section{Experimental Program}

In order to determining the strength and stiffness of HSS stud connectors, an experimental program is planned and executed. Although various codes and guidelines for push-out tests exist,[3-6], regarding medium strength steel studs. It has also been reported that the width of concrete slab in push-out specimens as per code[3] was inadequate for high strength steel studs. Later this code was superseded by the[5]) procedures. Even now, existing guidelines are also limited to the shapes, sizes and strength of concrete as well as steel sections. Method of casting of the concrete slab also vary among different codes of practice to conduct the push-out tests. Further the level of welded studs e.g.[3] have one level of stud shear connection while[5] recommends that stud should be welded at two levels to avoid any possibility of rotation of steel section during push-out test.

In the present study a new push-out test setup is proposed and based on this four push-out specimens S1, S2, S3, and S4 are tested under monotonic loading. The newness of this program is utilization of confined concrete strength in the design of concrete slab of push-out specimen. Due to the confinement effect it is found that even narrow width of concrete slab can be used for push-out test with HSS stud connectors. Figure 1 shows the typical push-out specimen having one level of studs in (a), along with sectional view at A-A in (b), and the forces developed are shown in (c). It can be seen that horizontal forces can be developed due to eccentricity between applied load and reaction at the base of RC slab.

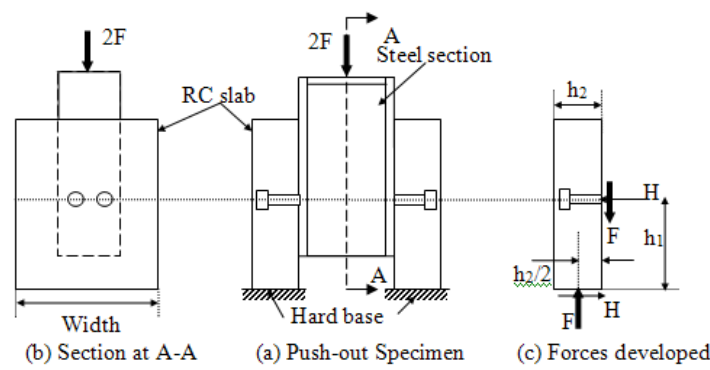

Figure 1. Typical push-out specimen and forces developed

\subsection{Basis for the Design of Push-out Specimen}

Authors are familiar about the guidelines recommended by[5] regarding the push-out tests. However due to the limitation of the testing facility, it was not possible to test the push-out specimen as per[5]. Since the strength of steel used in the stud connectors was $900 \mathrm{MPa}$ subjected to yield strength as $680 \mathrm{MPa}$. Therefore the ultimate load required to test the specimen was expected beyond the capacity of UTM $(1000 \mathrm{kN})$. To get rid of this difficulty authors have decided to weld connectors at one level, similar to the British code BS: 5400-1979. However the transverse reinforcement was modified as compared to code BS: 5400-1979 considering the enhancement in compressive strength of concrete. Authors have expected that the splitting of concrete slab can be avoided due to enhancement in its splitting resistance.

The reason for this was the hoop type transverse reinforcement having diameter of $10 \mathrm{~mm}$ at closer spacing. Further, the issue of anchorage of transverse reinforcement narrow width of concrete slab in push-out specimen was alleviated by providing rectangular hoops with adequate splicing length, see Figure 5(a).

\subsection{Confined Concrete Strength Model}

Various confinement strength model have been reported by[17] to predict the compressive fractured strength of con- 
fined column namely,[18]; Hoshikuma et al.; Hoppel et al.; Samaan et al.; Xiao and $\mathrm{Wu}$.; most of them experimentally validated. The Mander's model is reported as the most extensively used model for the confined concrete, hence it is adopted in the present work also.

\subsubsection{Mander Model}

Mander[18] derived relationship between the confined strength of concrete with equal confining stress in orthogonal directions (Appendix-1) and unconfined strength of the concrete. The application of this model is explained by[19] in the seismic designs of RC structural members as follows:

$$
K=\frac{f_{c c}^{\prime}}{f_{c}^{\prime}}=\left(-1.254+2.254+\sqrt{1+\frac{7.94 f_{l}^{\prime}}{f_{c}^{\prime}}}-2 \frac{f_{l}^{\prime}}{f_{c}^{\prime}}\right)
$$

Where,

$f_{c c}^{\prime}$ is compressive strength of confined concrete section, $f_{c}^{\prime}$ is strength of unconfined concrete and $f_{l}^{\prime}$ is effective confirming pressure due to transverse reinforcement as given by 2 (a).

$$
f_{l}^{\prime}=K_{e} f_{l}
$$

Where, $K_{e}$ is confinement effectiveness coefficient $[0.75$ for rectangular section[19]] and $f_{l}$ is lateral confining pressure on circular concrete section due to hoop reinforcement is determined as $2(b)$ :

$$
f_{l}=\frac{2 f_{y h} A_{s p}}{d_{s} s_{h}}
$$

Where $f_{y h}$ is yield strength of hoops, $A_{s p}$ is area of hoop having dimeter of $d_{s}$, and $s_{h}$ is longitudinal spacing of hoops.

\subsubsection{Confined stress and Ultimate Strain for Push-out slab}

For RC slab of push-out specimen having rectangular section with unequal effective confining stresses $f^{\prime}{ }_{l x}$ and $f^{\prime}{ }_{l y}$ are determined as follows:

Compression strength of confined concrete indirectly related to the effective confining stress that can be developed at yield of the transverse reinforcement which for rectangular section given by following expressions in Eqs. 2(c) and 2(d)[19]:

$$
\begin{aligned}
& f_{l x}^{\prime}=K_{e} \cdot \rho_{x} \cdot f_{y h} \\
& f_{l y}^{\prime}=K_{e} \cdot \rho_{y} \cdot f_{y h}
\end{aligned}
$$

Where, $K_{e}$ is confinement effectiveness coefficient, relating the minimum area of the effectively confined core to the nominal core area bounded by the centre line of hoop reinforcement. The value of $\mathrm{K}_{\mathrm{e}}$ is taken as 0.75 in the calculation as recommended by[19].

The strain at peak stress for confined concrete is obtained as 0.0095 using $2(\mathrm{e})$.

$$
\varepsilon_{c c}=0.002\left[1+5\left(\frac{f_{c c}^{\prime}}{f_{c}^{\prime}}-1\right)\right]
$$

The calculations for confined concrete strength and corresponding strain using Mander's model are shown in Appendix-1.
Considering the confined strength of concrete (63 MPa) as calculated using (1), it was expected that the splitting in concrete slab would not occur as the split tensile strength would also be enhanced by a factor 1.75 . In this way one may expect lesser material consumption as compared to[5] push-out specimen. Another aspect regarding the provision of stud connectors at two levels in[5] is taken care during testing of push-out specimen by arresting the Lateral movement of RC slabs.

\subsection{Fabrication of Modified Push-out Specimens}

Basically push-out specimens (Figure 2) consists of three main components namely steel beam, stud connector and reinforced concrete slab. The method used in the preparation of push-out specimens S1, S2, S3, and S4 in explained following sub sections:

\subsubsection{Steel Beam}

A mild beam section as shown in Figure 3 was fabricated in work shop. Dimensions of steel flange and web sections were adopted such that no buckling would occur. Uniform thickness of the flange in steel beam and web and flanges were welded together fabricated. Thickness of steel flanges was provided more than $40 \%$ of the diameter of the stud connector as recommended by[20].

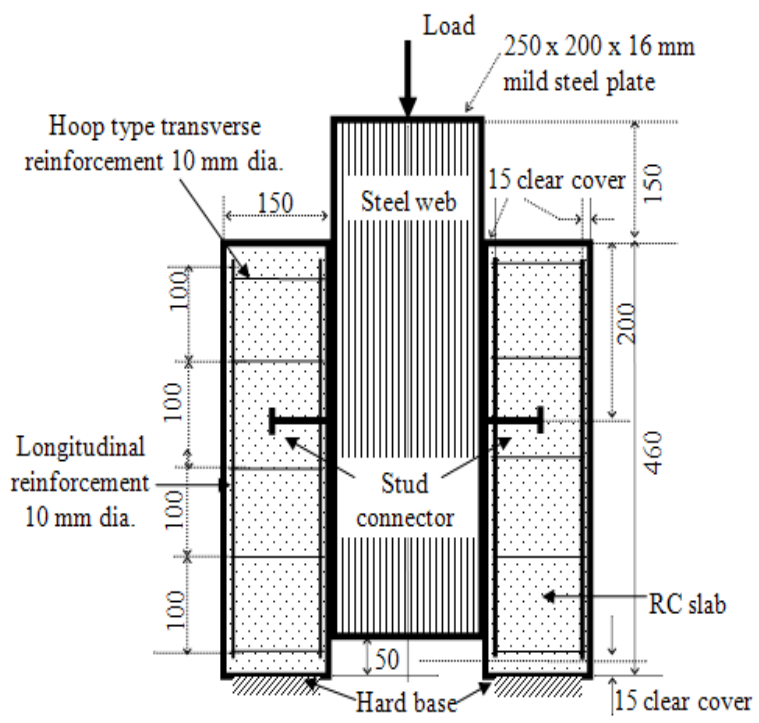

Figure 2. Details of reinforcement in modified push-out specimens

\subsubsection{Stud}

Stud type connectors prepared by machining from a steel (EN 19) rod of diameter $30 \mathrm{~mm}$. Stud type connector as shown in Figure 2, have $20 \mathrm{~mm}$ shank dia. $30 \mathrm{~mm}$ head dia. and length more than $4 \mathrm{~d}_{\mathrm{sh}}$ which were flexible and welded to the steel flanges. Basically flexible stud connectors transfer the forces at the interface through dowel action, Figure 3. It is known that the dowel action is achieved by the deformation of stud, hence results into slip at the interface. Therefore it is essential to understand the interface slip behaviour for 
such type of stud connectors. The stud shank at the base was chamfered to facilitate standard welding practice,[21].

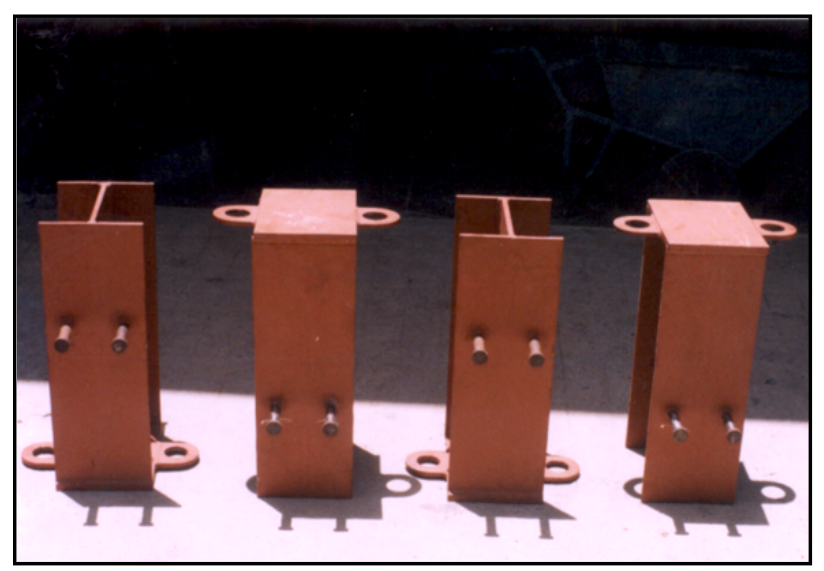

Figure 3. Fabricated steel section of push-out specimens

It is to be noted that stud (high strength steel) and flange (mild steel) of steel beam are welded using standard welding procedures recommended by American welding society (AWS). The distance of the stud from edge of beam was kept more than diameter of shank. Quality of welding was assured by the fabricator. To measure slip strain along stud shank, electrical resistance strain gauges were mounted on shank in longitudinal direction. The yield strength for HSS studs was determined based on $0.2 \%$ strain values obtained from coupon tests, as shown in Figure 4.

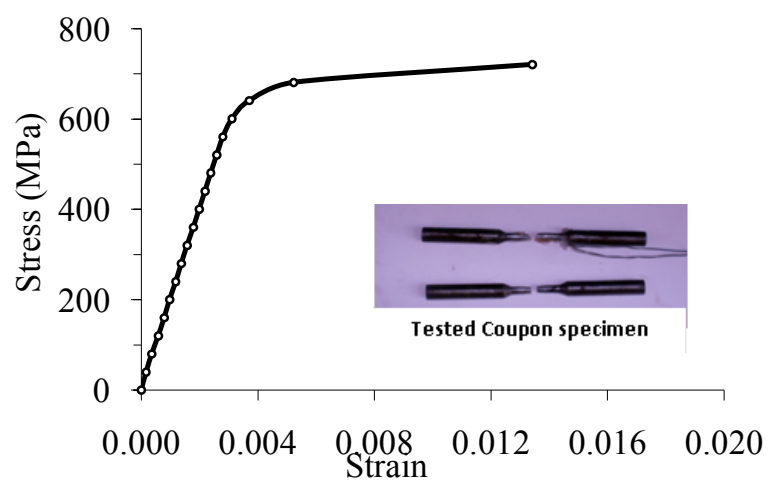

Figure 4. Stress-strain curve for HSS stud as per standard coupon tests

\subsubsection{RC Slab}

As explained earlier that narrow width RC slab $(300 \mathrm{~mm})$ is used in push-out specimens unlike[5] recommendation for increasing the width of concrete slab, in this study transverse reinforcement was provided such that splitting resistance got increase. For this purpose transverse reinforcement was provided as hoop.

\subsubsection{Casting of Concrete Slab}

Reinforcement grill were prepared as shown in Figure 5a. Then fabricated steel beam with welded stud and stiffeners were kept over bricks to facilitate a gap of $50 \mathrm{~mm}$. Form work made of $2 \mathrm{~mm}$ thin steel sheet used for concreting into slab, Figure 5b. After erecting reinforcement grill on both the side of steel beam, steel moulds were aligned (kept in position) enveloping the concrete grill. All gaps and joints were packed to avoid any leakage of slurry during concreting. To avoid any adhesion between concrete surface and steel form work, lubrication was applied at the inside surface of steel formwork.

Concrete (Table 1) is poured from top to case the concrete slab in vertical position.[5] recommends that the concrete slab must be cast in horizontal position for better comparison with actual slab casting in field. However there may be instances where stud connectors in horizontal direction are cast with concreting in vertical direction e.g. frames for seismic resistance.

Table 1. Properties of concrete mix

\begin{tabular}{|c|c|}
\hline Ingredients of concrete & Quantities specifications \\
\hline Concrete cylinder strength & $36 \mathrm{MPa}$ \\
\hline Concrete cube strength & $41.48 \mathrm{MPa}$ \\
\hline Cement type & $\mathrm{OPC}$ \\
\hline Cement & $300 \mathrm{~kg} / \mathrm{m}^{3}$ \\
\hline Fine aggregate & $325 \mathrm{~kg} / \mathrm{m}^{3}$ \\
\hline Coarse aggregate & $804 \mathrm{~kg} / \mathrm{m}^{3}$ \\
\hline Water & $165 \mathrm{litre} / \mathrm{m}^{3}$ \\
\hline Super Plasticizer & $250 \mathrm{ml}$ \\
\hline Water cement ratio & 0.55 \\
\hline
\end{tabular}

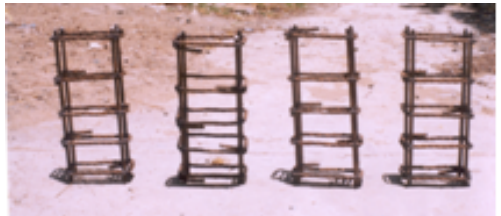

(a) Reinforcement in RC slab

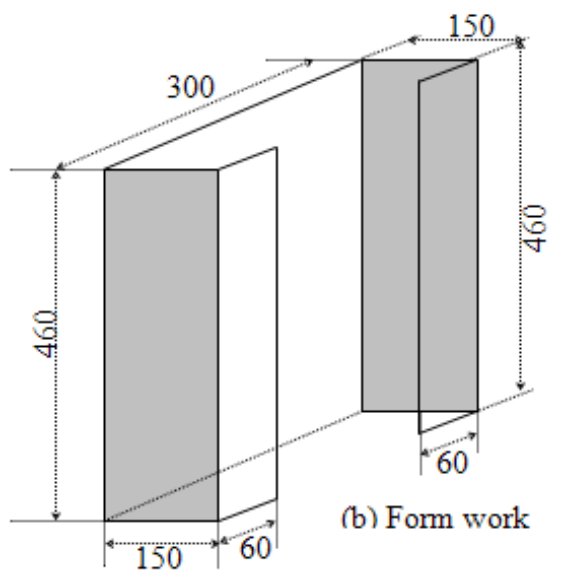

Figure 5. (a) Reinforcement (b) Steel form work for RC slab

For better compaction the concrete was poured in layers of about $150 \mathrm{~mm}$ thickness and each time needle type vibrator was used for proper compaction of concrete. After concreting was completed the specimens were kept for about 4 hours and then steel form work was removed. RC slab of specimen 
were covered with gunny bags and water was sprinkled frequently to maintain the wetness in concrete slabs. After curing of 28 days specimens were tested using UTM.

\subsection{Push-out Test Setup and Procedure}

\subsubsection{Modified Test set-up}

Push-out specimens after transportation from casting yard prepared for instrumentation and kept over a steel base plate (Figure 6). One angle section $100 \mathrm{~mm} \times 100 \mathrm{~mm} \times 12 \mathrm{~mm}$ size was welded with base plate at one end while other side free to adjust. Tie rods having $650 \mathrm{~mm}$ length and diameter $16 \mathrm{~mm}$ used for constraining lateral movement of RC slab with one end bolted head and the other as threaded ends as shown in Figure (6).

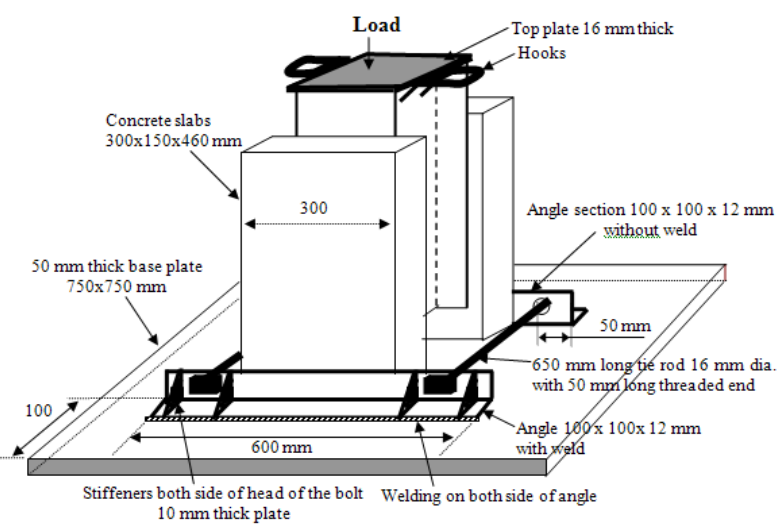

Figure 6. Schematic diagram of fixtures and arrangements for modified push-out test

\subsubsection{Instrumentation}

The surfaces of steel and concrete were cleaned and smoothened at the points for dial gauge and strain gauge readings. Dial gauges (DG) and strain gauges (SG) were mounted at critical locations as indexed in Figure (7).

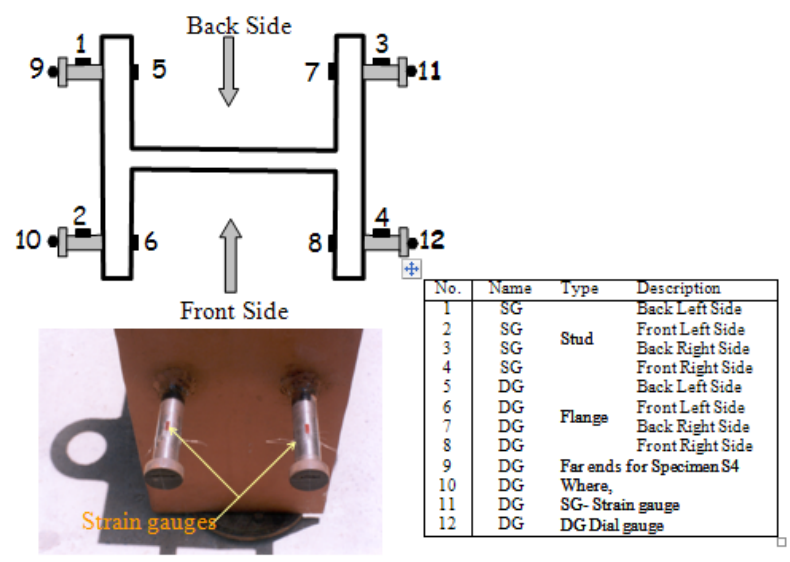

Figure 7. Instrumentation locations for push-out tests

\subsubsection{Test Procedure}

The assembly of test set-up (Figure 6) was kept between the frames of UTM. Steel tie rods was tightened sufficiently to avoid any movement at the base of slab. All electrical gauges were connected to the strain gauge conditioner. Dial gauges were mounted at the locations as specified in Figure 7. Adequate attention was paid to avoid any chance eccentric loading. Push-out specimens were tested using UTM of 1000 $\mathrm{kN}$ load capacity. Each specimen took about half an hour till it completely failed.

Initially the specimen was loaded upto about $25 \%$ of expected ultimate load $(550 \mathrm{kN})$ and then unloaded to zero. This was done to check the performance of the instruments mounted at the above specified locations. The load was increased till the failure of stud connectors. Interface slip between the steel flange and concrete slab was measured using dial gauges mounted by keeping tip in vertical direction. The strains in the transverse reinforcement bar in front of stud were recorded using strain recorder automatically. At the ultimate load cracking of concrete along with the local buckling of the flange was observed.

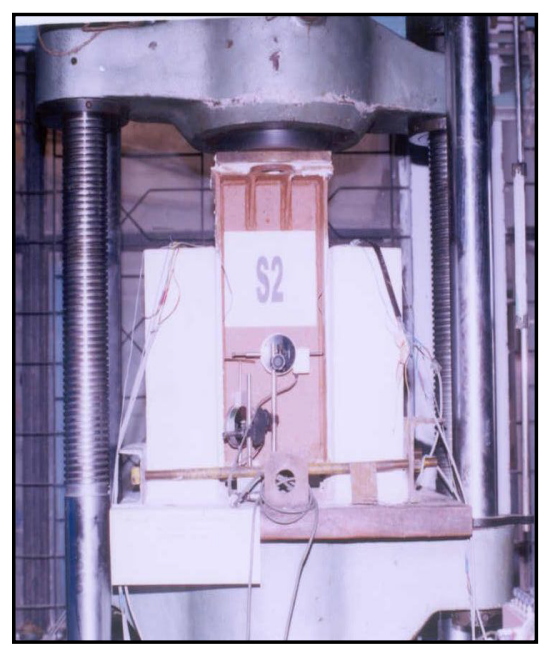

Figure 8. Push-out specimen under testing (Photo)

\section{Shear Strength and Stiffness of HSS Studs}

\subsection{Shear Strength}

The strength of stud shear connectors usually can be determined either by existing empirical equations or from push-out tests. The stud strength obtained from the push-out tests is reduced before it is used in design of composite girders.

\subsubsection{Strength in Push out Specimen}

Ollgaard[7] identified the important parameters that control the dowel strength of stud shear connectors. The mean dowel strength of stud shear connectors in push-out specimens in which the concrete slab had not failed prematurely through splitting shear. Maximum dowel strength $\left(D_{\max }\right)$ of the stud connectors can be determined empirically as (3):

$$
\left(D_{\max }\right)_{P u s h}=0.50 . A_{s h} \cdot \sqrt{f_{c} \cdot E_{c}}
$$

Where, $A_{s h}$ is area of shank, $f_{c}$ is compressive strength of concrete cylinder and $E_{c}$ is elastic modulus 
Push-out tests conducted by[8] to prove the hypothesis that the dowel strength increase with in tensile strength of material $f_{u}$, of stud connector. Considering variability of material into account maximum dowel strength in push-out specimens is given by (4).

$$
\left(D_{\max }\right)_{p u s h}=\left(5.3-\frac{1.3}{\sqrt{n}}\right) A_{s h} f_{u} \cdot\left(\frac{E_{c}}{E_{s}}\right)^{0.40} \cdot\left(\frac{f_{c}}{f_{u}}\right)^{0.35}
$$

Strength of stud in composite beams is reduced due to change in force transfer mechanism as compared that in push-out tests. This is reported to achieve by replacing constant value 5.3 in first bracket with 4.3. It can be seen in (4) that the maximum dowel strength depends on the strength of the stud shank, $A_{s h} f_{u}$ and the factors $\left(\frac{E_{c}}{E_{S}}\right)^{0.40}$ and $\left(\frac{f_{c u}}{f_{u}}\right)^{0.35}$ that allow for the interaction between the steel and the concrete.[20] has been reported that (4) is valid for a range of variables as given in Table 2. Modification factor $R_{f u}(5)$ to allow for variation in strength of stud steel was also proposed, in the case where stud steel has different strength $f_{u}$, than that used in push-out test $\left(f_{w}\right)_{\text {step }}$.

$$
R_{f u}=\left(\frac{f_{u}}{\left(f_{u}\right)_{\text {step }}}\right)^{0.65}
$$

Table 2. Range of variables for Eqs. (3) and (4)

\begin{tabular}{|l|c|l|c|}
\hline Variable Name & & Range & Units \\
\hline Elastic modulus of concrete & $\mathrm{E}_{\mathrm{c}}$ & $10000-33000$ & $\mathrm{MPa}$ \\
\hline Elastic modulus of Steel & $\mathrm{E}_{\mathrm{s}}$ & $200000-210000$ & $\mathrm{MPa}$ \\
\hline Compressive strength of & $\mathrm{f}_{\mathrm{c}}$ & $24<\mathrm{f}_{\mathrm{c}}<81$ & $\mathrm{MPa}$ \\
\hline Ultimate tensile strength of & $\mathrm{f}_{\mathrm{u}}$ & $430<\mathrm{f}_{\mathrm{u}}<640$ & $\mathrm{MPa}$ \\
\hline Height of stud connectors & $\mathrm{h}_{\mathrm{sh}}$ & $\mathrm{h}_{\mathrm{sh}} \geq 4 \mathrm{~d}_{\mathrm{sh}}$ & $\mathrm{mm}$ \\
\hline Thickness of weld collar & $\mathrm{t}_{\mathrm{wc}}$ & $\approx 0.31 \mathrm{~d}_{\mathrm{sh}}$ & $\mathrm{mm}$ \\
\hline
\end{tabular}

\subsection{Axial Strength of RC Slab in Push-out Specimens}

In this study the concrete slabs of push out specimens were restrained for any lateral movement. Therefore the moment due to eccentric load transfer the axial load carrying capacity will be lesser than that due to pure axial load. The axial load carrying capacity of the RC slab with minimum or no eccentricity is given by (6), given in[22]. The failure mode of concrete is considered as crushing under the axial load. Therefore ultimate axial load carrying capacity of specimen slabs is determined as per (6):

$$
P_{u}=0.4 f_{c k} A_{c}+0.67 f_{y} A_{s c}
$$

Substituting, $36 \mathrm{MPa}$ for characteristics strength of concrete $\mathrm{f}_{\mathrm{ck}}, 45000 \mathrm{~mm}^{2}$ for gross area concrete $\mathrm{A}_{\mathrm{c},}, 415 \mathrm{MPa}$ for $\mathrm{f}_{\mathrm{y}}, 314 \mathrm{~mm}^{2}$ for area of steel in compression $A_{\mathrm{sc}}$, the axial load carrying capacity of reinforced slab is obtained as $\mathrm{P}_{\mathrm{u}}$ as $735.30 \mathrm{kN}$. However, the force developed in push-out specimen slabs are not only axial but slight eccentricity may cause bending also Figure 1(c). But definitely the determination of the axial capacity of concrete slab is required to estimate the maximum actuator capacity to conduct the push-out tests.

Authors could not find clear description about utilization of confinement of concrete hence this effort is made to highlight this issue. The experimental results indicate that the failure of push out specimens was governed by the premature cracking due to splitting in concrete slab.

\subsection{Stiffness of HSS Stud Shear Connector}

\subsubsection{Load-slip Characteristics}

It has been reported by[20] that the ultimate strength of composite beams depends on strength and ductility of the shear connection. Therefore the load-slip behaviour of stud connection is considered important when a displacement is applied to the connector, there is an almost linear variation upto the load equal to 0.5 times of maximum dowel strength of studs. The slip is given by following (7) where units are in $\mathrm{N}$ and $\mathrm{mm}$ :

$$
\mathrm{S}_{0.5 \mathrm{Dmax}}=\left(80 \times 10^{-3}-86 \times 10^{-5} \mathrm{f}_{\mathrm{c}}\right) \cdot \mathrm{d}_{\mathrm{sh}}
$$

Further increase in load causes nonlinearity in slip which is followed by a plastic plateau at constant load $\left(D_{\max }\right)$ as shown in Figure 8. Eventually it fails at the load value of $95 \%$ of ultimate with a slip of about $40 \%$ of diameter of shank of HSS stud. Thus Figure 9 show typical load-slip characteristics of the stud shear connectors in the push-out specimen.

Determination of true stiffness is of importance to engineers who are involved in performance evaluation of stud shear connector in existing SCC bridges. During the bridge inspection a site engineers invariably measures tangent stiffness which gives an over estimation of the three stiffness $\mathrm{K}_{\mathrm{s}}$ and stiffness which is even larger than the initial stiffness $\mathrm{K}_{\mathrm{si}}$. The only way to measure the true stiffness for second stiffness from the origin $\mathrm{K}_{\mathrm{s}}$ is to instrument the bridge when it is first constructed. $\mathrm{K}_{\mathrm{si}}$ is sometimes used to determine the force on connectors that are induced by the shrinkage of concrete or thermal changes in steel and concrete.

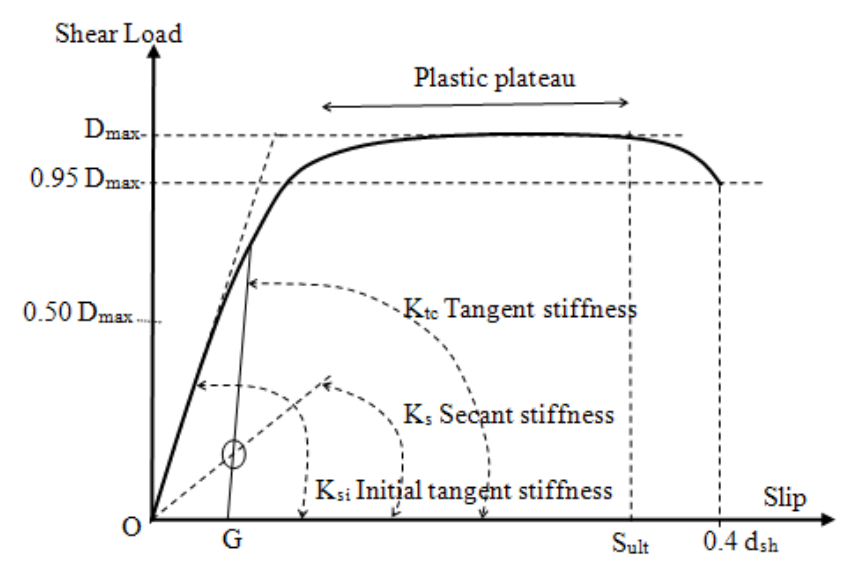

Figure 9. Typical load-slip characteristic of stud in push-out test

Initial tangent stiffness $\mathrm{K}_{\mathrm{si}}$ is assumed to be the stiffness at $0.5 \mathrm{D}_{\max }$ and hence stiffness reported by[23] as:

$$
\mathrm{K}_{\mathrm{si}}=\frac{\mathrm{D}_{\max }}{\mathrm{d}_{\mathrm{sh}}\left(\alpha-0.0017 \mathrm{f}_{\mathrm{c}}\right)}
$$

Where, $d_{\text {sh }}$ is diameter of shank and constant $\alpha$ range takes values $0.08,0.16$ and 0.24 for upper $95 \%$ characteristic stiffness, mean stiffness and lower characteristic stiffness respectively, It can be noticed that ultimate slip decreases 
with increase in compressive strength of concrete $\mathrm{f}_{\mathrm{c}}$. Substituting $\mathrm{D}_{\max }$ equal to $132000 \mathrm{~N}, \mathrm{f}_{\mathrm{c}}$ equal to $36 \mathrm{MPa}$ and diameter of shank equal to $20 \mathrm{~mm}$, shear stiffness for various $\alpha$ value are tabulated in Table 4 . It is found that the experimental value Table 3 of shear stiffness is closer to the mean stiffness for HSS stud connector sees Table 4.

\section{Results and Discussion}

\subsection{Interface Slip}

Load versus interface slip curves for all the four push out specimens are plotted in Figure 10. Mean slip at maximum load was obtained from push-out tests about $6 \mathrm{~mm}$ which is less than $40 \%$ of the diameter of stud shank $(8 \mathrm{~mm})$.

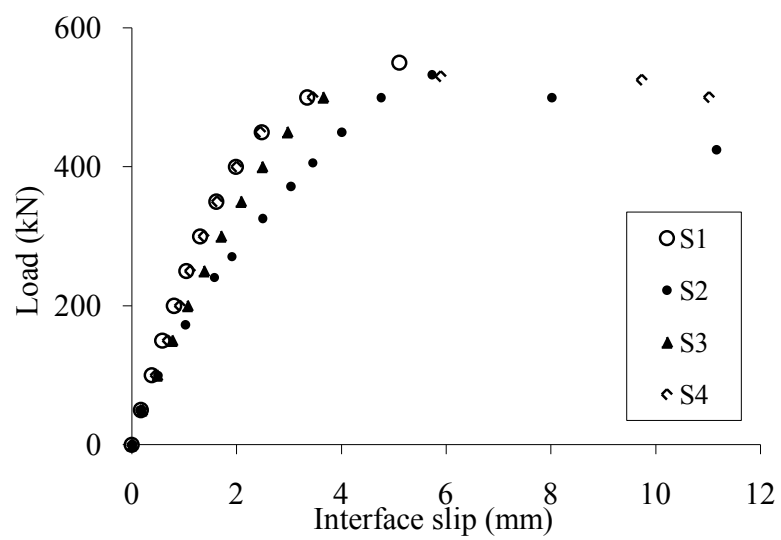

Figure 10. Load-slip behaviour for HSS studs in push-out specimens

\subsection{Stiffness}

The static shear stiffness of the stud shear connection as obtained experimentally is given in Table 3 and stiffness based on empirical relations[23] are compared in Table 4.

Table 3. Shear stiffness of stud shear connection

\begin{tabular}{|c|c|c|c|c|c|}
\hline \multirow{2}{*}{$\begin{array}{c}\text { Speci } \\
\text { men }\end{array}$} & $\begin{array}{c}\text { Shear } \\
\text { resistance } \\
\text { of speci- } \\
\text { men }\end{array}$ & $\begin{array}{c}\text { Slip } \\
\text { at } \\
\text { Max. } \\
\text { load }\end{array}$ & $\begin{array}{c}\text { Slip at } \\
50 \% \\
\text { of } \\
\text { Max. } \\
\text { load }\end{array}$ & $\begin{array}{c}\text { Stiffness of } \\
\text { shear con- } \\
\text { nection }\end{array}$ & $\begin{array}{c}\text { Ulti- } \\
\text { mate } \\
\text { slip } \\
\text { w.r.t. } \\
\mathrm{d}_{\text {sh }}\end{array}$ \\
\hline S1 & 550 & 5.11 & 1.185 & 234.69 & 25.55 \\
\hline S2 & 533 & 5.73 & 1.910 & $139.53^{\#}$ & 28.65 \\
\hline S3 & 500 & 3.65 & 1.380 & 181.15 & 18.25 \\
\hline S4 & 530 & 5.89 & 1.184 & 223.81 & 29.45 \\
\hline \multicolumn{7}{|r|}{ \# Value for specimen S2 is discarded for stiffness calculation. } \\
\hline
\end{tabular}

\subsection{Strain Responses}

\subsubsection{Shank Strain}

For specimen S1, strain along shank is only $800 \mu \varepsilon$ (Figure
13). Referring Figure 7, negative strains in the left hand side (LHS) front stud and right hand side (RHS) back stud shows that compressive strain can also develop although lesser in magnitude.

Specimen S2 showed maximum recorded shank strain about 6000 micro strain which is tensile in nature. In specimen S3 shank strain show some kind of inflexion as the strain sign change occur. This inflexion of strain in the shank shows that the stud connector may undergo deformation in double curvature. Secondly, it may also be possible due to redistribution of load.

Table 4. Shear stiffness of HSS stud connector

\begin{tabular}{|c|c|c|c|}
\hline \multicolumn{3}{|c|}{ Stud Shear Stiffness (kN/mm) } \\
\hline Stiffness value & $\alpha$ & $\begin{array}{c}\text { As per } \\
\text { eq. (8) }\end{array}$ & $\begin{array}{c}\text { Experimental } \\
\text { As per Table 3 }\end{array}$ \\
\hline Mean & 0.16 & 66.80 & \\
\hline $\begin{array}{c}\text { Upper 95\% char- } \\
\text { acteristics }\end{array}$ & 0.08 & 351.06 & $\begin{array}{c}\text { 213.220/4 }=53.304 \\
\text { (Value is closer to mean } \\
\text { value) }\end{array}$ \\
\hline $\begin{array}{c}\text { Lower characteris- } \\
\text { tics }\end{array}$ & 0.24 & 36.91 & \\
\hline
\end{tabular}
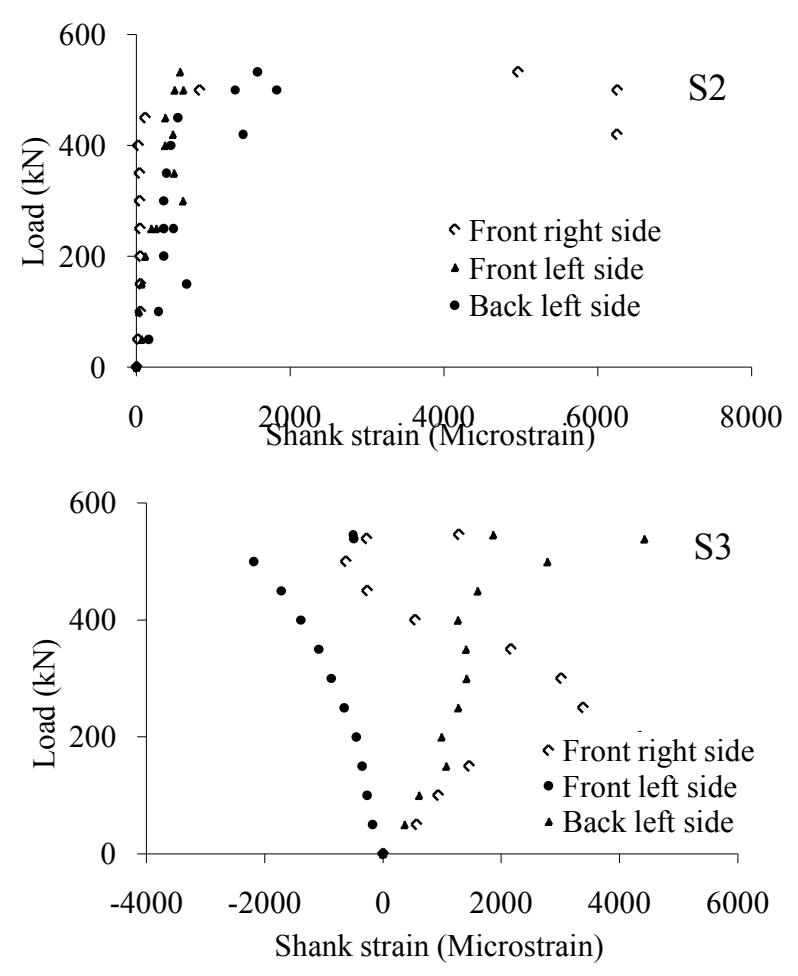

Figure 11. Strain in shank of the stud in longitudinal direction

\subsubsection{Strain in Transverse Reinforcement}

Maximum longitudinal strain in reinforcement bars of specimen $\mathrm{S} 1$ is recorded as 2250 microstrain. This indicates that yielding in the transverse reinforcement has occurred 
near the maximum load bar as shown in Figure 12.

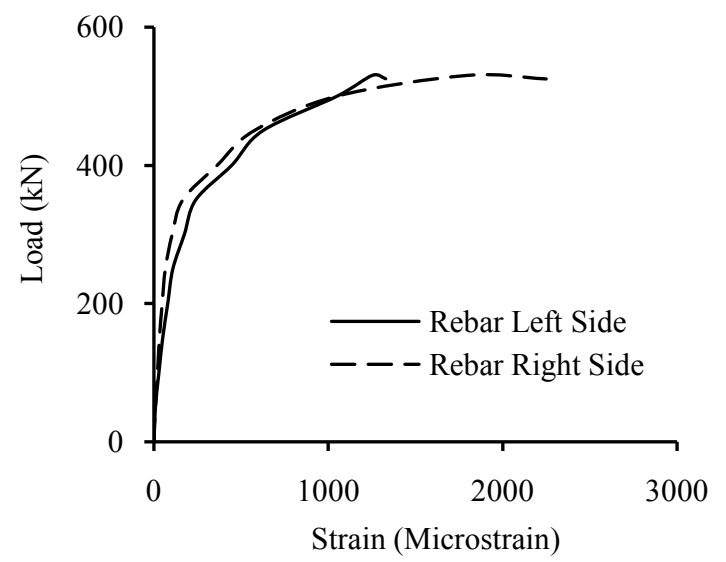

Figure 12. Strains in transverse reinforcement bar near HSS stud

\subsection{Observations Made During Push-out Test}

The cracking patterns during each load increment were carefully observed to see failure mechanism. In all the push out specimens first of all the interface cracks on both the sides were observed at about $30 \%$ of the ultimate failure load. Secondly cracks in horizontal direction (i.e. along width of concrete slab) started appearing at the level of shear connectors. It was also noted during experiments that slight variation about $0.5 \mathrm{~mm}$ in flanges thickness of the steel beam, induced slight buckling of the thinner flanges of S2 specimen, at about $90 \%$ of the ultimate failure loads. Failure of concrete slab in specimen S1, started due to spalling of concrete at the corner of slabs Figure 13. Gradually the cracking of concrete slab caused the failure of stud shear connectors by fracture at ultimate load. In specimen S2 and S3, concrete slab showed lesser cracks and the specimens failed by fracture of both the stud shear connectors embedded in one side of concrete slab as shown in Figure 13.
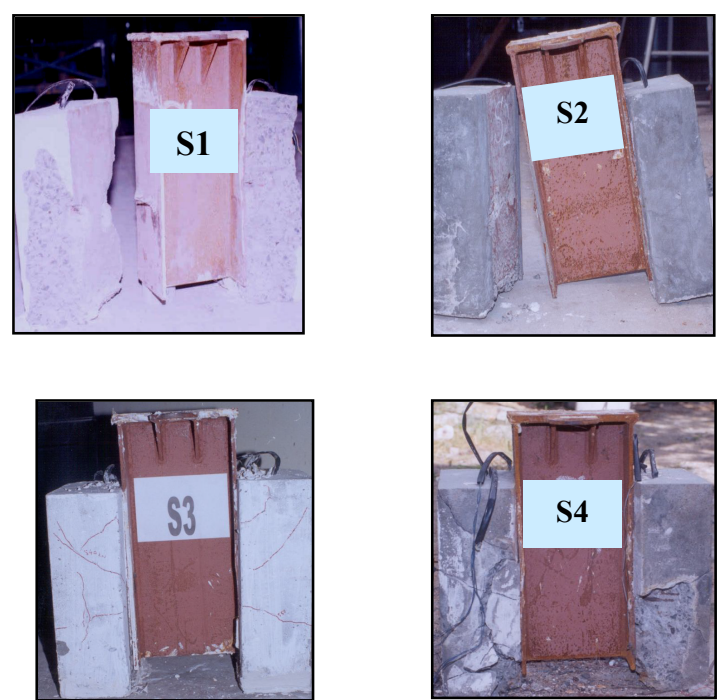

Figure 13. Tested push-out specimens (photos)

\subsection{Strength of HSS Stud}

The ultimate shear resistance of all the four push out specimens $\mathrm{S} 1, \mathrm{~S} 2, \mathrm{~S} 3$, and $\mathrm{S} 4$ as obtained from the experiment were $550 \mathrm{kN}, 533 \mathrm{kN}, 500 \mathrm{kN}$ and $530 \mathrm{kN}$ respectively. Therefore average ultimate load for push out specimens evaluated as $528 \mathrm{kN}$. Thus ultimate shear resistance of HSS stud was considered as one fourth of $528 \mathrm{kN}$ that is $132 \mathrm{kN}$. Experimental values obtained in this study are relatively compared with codes[3-6] and values are compared in Table 5. Because of the variation in stud material strengths used in this study as compared to codal values, the exact comparison of ultimate shear strength is not possible. Therefore ultimate shear strengths of the studs are relatively compared in this study for similar grade of concrete.

\subsubsection{Strength as per[5, 24]}

It is to be noted that, the characteristic ( $5 \%$ lower fractile) resistance of these specimens is given by the Eurocode[5] as follows:

Shear resistance of a HSS stud connector in a solid slab[5] is determined by following (9):

$$
P_{R D}=\frac{0.8 f_{u} \cdot\left(\pi d^{2} / 4\right)}{\gamma_{v}}
$$

Where, ultimate strength of steel $f_{w}$, is $900 \mathrm{MPa}$, diameter of shank d, is $20 \mathrm{~mm}$, and $\gamma_{\mathrm{v}}$ is 1.25 . Substituting the values in (9), we get, $\mathrm{P}_{\mathrm{RD}}$ equal to $180.96 \mathrm{kN}$. Similarly,

$$
P_{R D}=\frac{0.29 d^{2}\left(f_{c k} E_{c m}\right)^{0.5}}{\gamma_{v}}
$$

Where, concrete strength (cube) $f_{c k}$ is $41.48 \mathrm{MPa}$, Secant modulus of concrete $E_{c m} 5000 \sqrt{ }(41.48)$ equals to 32202.5 $\mathrm{MPa}$, factor $\gamma_{\mathrm{v}}$ is 1.25 .

Substituting the above values in (10), we get, $\mathrm{P}_{\mathrm{RD}}$ equal to $107.25 \mathrm{kN}$. It is recommended that the minimum values obtained from the Eqs. (9) and (10), is considered as characteristic resistance of the studs. Eqs. (9) and (10) show lot of variation in shear resistance depending upon concrete and steel properties.

Table 5. Comparison of HSS stud shear strengths

\begin{tabular}{|c|c|c|c|c|}
\hline \multicolumn{5}{|c|}{ Ultimate shear strength of shear connectors $(\mathrm{kN})$} \\
\hline $\begin{array}{c}\text { Stud } \\
\text { Size }\end{array}$ & $\begin{array}{c}\text { BS:5400 } \\
-1979 \\
\text { part-5 }\end{array}$ & $\begin{array}{c}\text { Present } \\
\text { Experiments }\end{array}$ & $\begin{array}{c}\text { Euro- } \\
\text { code }\end{array}$ & $\begin{array}{c}\text { Indian Code } \\
\text { IS:11384-1985 }\end{array}$ \\
\hline $20 \times 100$ & - & 132 & 107 & $\left(112^{*}\right)$ \\
\hline $19 \times 100$ & 109 & - & - & - \\
\hline $\begin{array}{c}\text { * The value given in Indian code is } 67 \% \text { of ultimate strength, therefore } \\
75 \text { /0.67 = 112 } \mathrm{kN} \text {, while BS: 5400 gives nominal static strength which } \\
\text { is minimum ultimate strength out of three push out tests. }\end{array}$ \\
\hline
\end{tabular}

\section{Conclusions}

Modified push-out tests have been conducted to determine shear strength and stiffness of HSS studs. Confinement strength contribution (using Mander's Model) to enhance the splitting resistance of reinforced concrete slab due to hoop type transverse reinforcement has been briefly discussed. Analysis of push-out test data was carried out and values of 
shear strength are compared with that recommended by Eurocode 4. In addition to that few empirical expressions recommended in literature to determine the shear strength of stud type connectors in push out specimens have also been utilized.

Experimental results showed that the average shear strength of HSS stud connectors used in this study was $132 \mathrm{kN}$ (which is quite comparable with the Eurocode 4 values), and the average static stiffness equal to $53.3 \mathrm{kN} / \mathrm{mm}$ which is found closer to the mean value given in literature.

It can be concluded from present experimental study that confinement of concrete in the vicinity of HSS stud significantly enhanced the compressive strength as well as splitting resistance of concrete. Therefore it must be considered while designing concrete slab for pushout specimens.

Cracking in concrete slabs of push-out specimens at stud connector level has been observed first and eventually failure occurred with the fracture of HSS stud connectors. Therefore it can be inferred that in the design of reinforced concrete slab for push out tests specimens confined compressive strength should be considered.

It was observed that two out of four specimens showed good post peak behaviour while other two specimens could reach upto maximum capacity (i.e. $550 \mathrm{kN}$ ). Further improvements are possible by the addition of steel fibres concrete in the vicinity of HSS studs embedded in RC slab of push-out specimens.

\section{APPENDIX-1}

\section{A.1. Determination of Confined Compressive Strength and Strain for Concrete}

Using Mander's model confined compressive strength of the concrete slab (Figure A1) is calculated as follows (refer,[19]):

Area of cross-section of transverse bars $\left(\mathrm{A}_{\mathrm{b}}\right)$ is equals to:

$\mathrm{A}_{\mathrm{b}}=\frac{\pi}{4} \times 10^{2}=78.5 \mathrm{~mm}^{2}$

Reinforcement ratio in $\mathrm{y}$ direction, $\rho_{y}$ : $\rho_{\mathrm{y}}=\frac{2 \mathrm{~A}_{\mathrm{b}}}{\mathrm{s.h}}=\frac{2 \times 78.54}{100 \times 300}=0.00523$

Spacing of transverse reinforcement $\mathrm{S}=100 \mathrm{~mm}$

$$
\rho_{\mathrm{x}}=\frac{2 \mathrm{~A}_{\mathrm{b}}}{\mathrm{s.h}_{\mathrm{y}}}=\frac{2 \times 78.54}{100 \times 150}=0.0105
$$

Let, $\mathrm{K}_{\mathrm{e}}=0.75, \mathrm{f}_{\mathrm{yh}}=415 \mathrm{MPa}, \mathrm{f}_{\mathrm{c}}^{\prime}=36 \mathrm{MPa}$

$$
\begin{gathered}
f_{c x}^{\prime} / f_{c}^{\prime}=0.75 \times 0.0105 \times \frac{415}{36}=0.09078 \\
f_{c y}^{\prime} / f_{c}^{\prime}=0.75 \times 0.00523 \times \frac{415}{36}=0.0452 \\
K=\frac{f_{c c}^{\prime}}{f_{c}^{\prime}}=1.75 \quad \text { (Value as per[19]) }
\end{gathered}
$$

Compressive strength of confined concrete $\mathrm{f}_{\mathrm{cc}}^{\prime}=1.75 \times 36=63 \mathrm{MPa}$

\section{A.2. Strain at Peak Compressive Stress}

Strain at the peak confined compressive strain as per Mander's model is calculated as follows:

$$
\begin{aligned}
& \varepsilon_{c c}=0.002\left[1+5\left(\frac{f_{c c}^{\prime}}{f_{c}^{\prime}}-1\right)\right] \\
= & 0.002\left[1+5\left(\frac{63}{36}-1\right)\right]=0.0095
\end{aligned}
$$

At peak compressive stress the value of strain is obtained as 0.0095 . Normally for unconfined concrete the strain value corresponding to peak stress is considered as 0.002 and ultimate strain as 0.0035 .

\section{ACKNOWLEDGEMENTS}

Support rendered by staff of advanced material laboratory, CSIR-SERC, during this study is highly acknowledged. Motivation provided by Dr. J. Rajasankar for writing this paper is duly acknowledged. This paper is being published with the permission of the Director, CSIR-Structural Engineering Research Centre, Chennai, (India).

\section{REFERENCES}

[1] Moore, W. P. Jr., C.D. Buckner and I. M. Viest, (1988), “An Overview of Composite Construction in the United States", Composite Construction in Steel and Concrete, ASCE, New York, 1-17.

[2] Viest, I. M., Easterling W. S. and Morris, W. M. K., (1992), "Composite Construction: Recent Past, Present and Near Future, in Composite Construction in Steel and Concrete, 2nd ed., ASCE, New York, 1-16.

[3] BS: 5400, (1979), Steel, concrete and composite bridges: Part 5: Code of practice for design of composite bridges, London, British Standards Institution.

[4] IS: 11384-1985, Code of practice for composite construction in structural steel and concrete, Bureau of Indian Standard, New Delhi.

[5] DD ENV 1994-1-1, Design of composite steel and concrete structures- Part 1.1, EC 4: General rules and rules for building, London: British Standards Institution.

[6] AISC, (2005), "Specification for structural steel buildings", ANSI/AISC 360-05, American Institute of Steel Construction.

[7] Ollgaard, J.G., Slutter R. G. and Fisher J.W., (1971), "Shear strength of stud connectors in lightweight and normal weight concrete", Engineering Journal AISC, Vol. 8, 55-64.

[8] Hawkins, N. M., (1973), "The strength of stud shear connectors", Civil Engineering Transactions, Institution of Engineers, Australia, Vol. CE33, 46-52. 
[9] Oehlers, D. J. and Johnson, R. P., (1987), "The strength of stud shear connections in composite beams", The Structural Engineer, June, Part B.

[10] Lloyd, R. M. and Wright, H. D., (1990), "Shear connection between composite slabs and steel beams", Journal of Structural Engineering, 255-285.

[11] Shim, C. S., Lee, P. G. and Yoon, T. Y. (2004), "Static behaviour of large stud shear connectors", Engineering Structures, Vol. 26, Issue 12, 1853-1860.

[12] Oehlers, D. J. and Park, S. M., (1992), "Shear connectors in composite beams with longitudinally cracked slabs", Journal of Structural Engineering, Vol. 118, No. 8， 2004-2022.

[13] Li, A., and Cederwall, K., (1996), "Push-out Tests on Studs in high strength and normal strength concrete", Journal of Constructional Steel Research, vol. 36 No. 1, 15-29.

[14] Bro, M. and Westberg, M., (2004), Influence of fatigue on headed stud connectors in composite bridges, Master's thesis, department of civil \& environmental engineering, Lulea University of Technology Sweden, May.

[15] Pallares, L. and Hajjar, J. F., (2010), "Headed steel stud anchors in composite structures", Part I: shear, Journal of Constructional Steel Research, vol. 66, 198-212.

[16] Lam, D. and El-Lobody, E., (2005), "Behaviour of headed stud shear connectors in composite beam", Journal of Struc- tural Engineering, ASCE, Vol. 131, No.1, 96-107.

[17] Lin H. J., and Liao C. I., (2004), "Compressive strength of reinforced concrete column confined by composite material", Composite Structures, 65, 239-250.

[18] Mander, J. B., Priestley, M. J. N., and Park, R., (1988), "Theoretical stress-strain model for confined concrete", Journal of Structural Engineering, 114(8), 1804-26.

[19] Paulay, T. and Priestley, M.J.N., (1992), Seismic design of reinforced concrete and masonry building, John Wiley \& sons, Inc.

[20] Oehlers, D. J. and Bradford, M.A., (1995), Composite steel and concrete structural members: Fundamental Behaviour, Pergamon Press, Oxford, first edition.

[21] AWS, (2006), Structural welding code, American welding society.

[22] Karve, S. R. and Shah, V. L., (1994), Limit state theory and design of reinforced concrete, reprint, Structures Publishers, Pune, India.

[23] Oehlers, D. J. and Coughlan, C. G., (1986), "The shear stiffness of stud shear connections in composite beams", Journal of Constructional Steel Research, vol. 6, 273-284.

[24] Johnson, R. P. and Anderson, D., (1993), Designer's Handbook to Eurocode 4-part 1.1, Design of composite steel and concrete structures. 